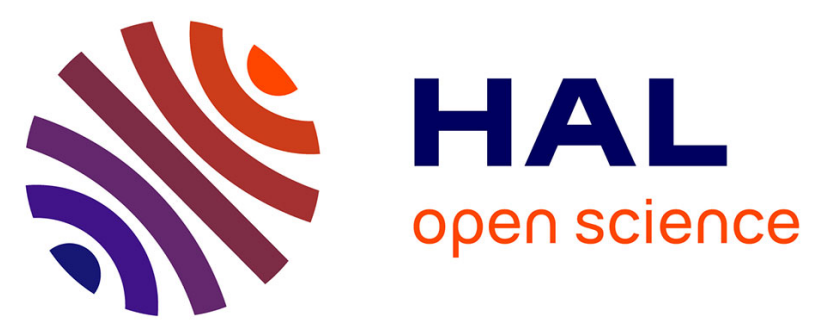

\title{
1-Aminobicyclo[2.2.2] octane-2-carboxylic acid and derivatives as chiral constrained bridged scaffolds for foldamers and chiral catalysts
}

Pierre Milbeo, Jean Martinez, Muriel Amblard, Monique Calmès, Baptiste Legrand

\section{To cite this version:}

Pierre Milbeo, Jean Martinez, Muriel Amblard, Monique Calmès, Baptiste Legrand. 1Aminobicyclo[2.2.2] octane-2-carboxylic acid and derivatives as chiral constrained bridged scaffolds for foldamers and chiral catalysts. Accounts of Chemical Research, 2021, 54 (3), pp.685-696. 10.1021/acs.accounts.0c00680 . hal-03371473

\section{HAL Id: hal-03371473 \\ https://hal.science/hal-03371473}

Submitted on 8 Oct 2021

HAL is a multi-disciplinary open access archive for the deposit and dissemination of scientific research documents, whether they are published or not. The documents may come from teaching and research institutions in France or abroad, or from public or private research centers.
L'archive ouverte pluridisciplinaire HAL, est destinée au dépôt et à la diffusion de documents scientifiques de niveau recherche, publiés ou non, émanant des établissements d'enseignement et de recherche français ou étrangers, des laboratoires publics ou privés. 


\title{
1-Aminobicyclo[2.2.2]octane-2-carboxylic acid and derivatives as chiral constrained bridged scaffolds for foldamers and chiral catalysts
}

\author{
PIERRE MILBEO, JEAN MARTINEZ, MURIEL AMBLARD*, MONIQUE \\ CALMES*, BAPTISTE LEGRAND* \\ Institut des Biomolécules Max Mousseron, IBMM, University of Montpellier, ENSCM, \\ CNRS, Montpellier, France. http://ibmmpeptide.com/
}

RECEIVED ON DATE GOES HERE.

\section{CONSPECTUS}

The improvement of molecular diversity is one of the major concerns of chemists since the continuous development of original synthetic molecules provides unique scaffolds usable in organic and bioorganic chemistry. The challenge is to develop versatile platforms with highly controlled chemical three-dimensional space thanks to controlled chirality and conformational restraints. In this respect, cyclic $\beta$-amino acids are of great interest with applications in various fields of chemistry. Beside intrinsic biological properties, they are important precursors for the synthesis of new generations of bioactive compounds such as

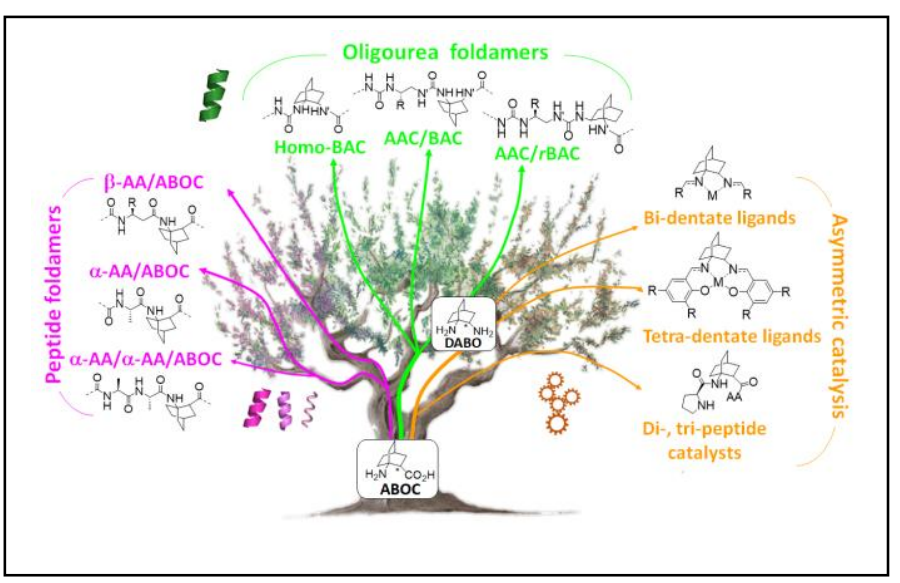
antibiotics, enzyme inhibitors and antitumor agents.

They have also been involved in asymmetric synthesis as efficient organo-catalysts in their free form and as derivatives. Finally, constrained cyclic $\beta$-amino acids have been incorporated into oligomers to successfully stabilize original structures in foldamer science with recent successes in health, material science and catalysis. Over the last $\sim 10$ years, we focused on bicyclic $\beta$-amino acids possessing a bicyclo[2.2.2]octane structure. This latter is a structural key element in numerous families of biologically active natural and synthetic products and is an interesting template for asymmetric synthesis. Nonetheless, reported studies on bicyclic carbo-bridged compounds are rather limited compared to those on bicyclic-fused and hetero-bridged derivatives. In this Account, we particularly focused on the synthesis and applications of the 1-aminobicyclo[2.2.2]octane-2-carboxylic acid, named ABOC, and its derivatives. This highly constrained bicyclic $\beta$-amino acid, with a sterically hindered bridgehead primary amine and an endocyclic chiral center displays drastically reduced conformational freedom. In addition, its high bulkiness strongly impacts the spatial orientation of the appended functionalities and the conformation of adjacent building blocks. Thus, we have first expanded a fundamental synthetic work by a wide ranging study in the field of foldamers, in the design of various stable peptide/peptidomimetic helical structures incorporating the ABOC residue (11/9-, 18/16-, 12/14/14- and 12/10-helices). In addition, such bicyclic residue was fully compatible with and stabilized the canonical oligourea helix whereas very few cyclic $\beta$-amino acids have been incorporated into oligoureas. Besides, we have pursued with the synthesis of some ABOC derivatives, in particular the 1,2-diaminobicyclo[2.2.2]octane chiral diamine, named DABO, and its investigation in chiral catalytic system. Covalent organo-catalysis of the aldol reaction using $\mathrm{ABOC}$ containing tripeptide catalysts provided a range of aldol products with high enantioselectivity. Moreover, the double reductive condensation of DABO with various aldehydes allowed to build new chiral ligands that proved their efficiency in the copper-catalysed asymmetric Henry reaction. 


\section{KEY REFERENCES}

André, C.; Legrand, B.; Deng, C.; Didierjean, C.; Pickaert, G.; Martinez, J.; Averlant-Petit, M. C.; Amblard, M.; Calmes, M. (S)-ABOC: A Rigid Bicyclic $\beta$-Amino Acid as Turn Inducer. Org. Lett. 2012, 14 (4), 960-963. ${ }^{1}$ An extensive structural study in solution and in the solid-state demonstrating that the 1-Aminobicyclo[2.2.2]octane-2-carboxylic acid (ABOC) constituted a novel scaffold able to induce a highly stable reverse-turn when incorporated in central position of tripeptides.

Legrand, B.; André, C.; Wenger, E.; Didierjean, C.; Averlant- Petit, M. C.; Martinez, J.; Calmes, M.; Amblard, M. Robust Helix Formation in a New Family of Oligoureas Based on a Constrained Bicyclic Building Block. Angewandte Chemie 2012, 124 (45), 11429-11432. ${ }^{2}$ Oligomers of constrained bicyclo[2.2.2]octane motifs connected via urea linkages adopt robust 2.5 12/14 oligoureas helices with unique properties.

Legrand, B.; André, C.; Moulat, L.; Didierjean, C.; Hermet, P.; Bantignies, J.-L.; Martinez, J.; Amblard, M.; Calmès, M. 12/14/14-Helix Formation in 2:1 $\alpha / \beta$-Hybrid Peptides Containing Bicyclo[2.2.2]Octane Ring Constraints. Chemistry - A European Journal 2016, 22 (34), 1198611990. ${ }^{3}$ The 2:1 $\alpha$-AA/ABOC peptide foldamers displayed $\alpha$-amino acid side chains in a spatial arrangement comparable to those in the $\alpha$-helix and thus, could serve as $\alpha$-helix mimics for biological applications.

Milbeo, P.; Moulat, L.; Didierjean, C.; Aubert, E.; Martinez, J.; Calmès, M. C1-Symmetric 1,2Diaminobicyclo[2.2.2] Octane Ligands in Copper-Catalyzed Asymmetric Henry Reaction: Catalyst Development and DFT Studies. European Journal of Organic Chemistry 2018, 2018 (2), 178-187. ${ }^{4}$ The 1,2-diaminobicyclo[2.2.2]octane scaffold was used to design original 
ligands whose combined with $\mathrm{Cu}(\mathrm{OAc})_{2}$ led to efficient catalysts for the asymmetric Henry reaction of nitromethane with various aldehydes.

\section{INTRODUCTION}

$\beta$-amino acids are of great interest in various fields of organic and bioorganic chemistry such as medicinal, supramolecular chemistry and asymmetric catalysis. ${ }^{5}$ They have been frequently found in numerous bioactive natural products from various microorganisms and are essential monomers in natural antitumor agents such as taxol and bleomycin. ${ }^{6,7}$ Compared to the common $\alpha$-amino acids, they possess one extra backbone carbon atom, which improved their stability and, $\beta$-peptides are inert to proteases. Consequently, they have been widely incorporated into peptides to generate peptidomimetics exhibiting significantly improved pharmacokinetic profiles. Furthermore, the early works from Seebach, Gellman, and co-workers have shown that $\beta$-amino acid oligomers can fold into original architectures reminiscent of the protein secondary structures, and gave rise to the field of foldamers. ${ }^{8-10}$ In this context, great efforts have been made to enlarge the $\beta$-amino acid family by developing conformationally constrained cyclic $\beta$ amino acids. ${ }^{11}$ To date, a broad range of single ring systems of different sizes have been synthesized and successfully used as precursors of various bioactive compounds such as antibiotics, enzyme inhibitors, antitumoral compounds. ${ }^{12,13}$ They have also been involved in asymmetric synthesis as efficient organo-catalysts both in their free form and their derivatives. ${ }^{14,15}$ Their incorporation into oligomers significantly enlarged the diversity of foldamer structures, and allowed the development of innovative foldamers as therapeutic candidates ${ }^{16}$ as well as catalysts of complex chemical reactions. ${ }^{17}$ 
Over the past ten years, we focused on highly constrained amino acids built around a bicyclo[2.2.2] octane structure. Bicyclic molecules are less flexible and bulkier than single-ring compounds, and such a strengthened conformational restriction has been successfully used in the optimization of relevant molecules. Some bioactive natural and synthetic products containing a bicyclo[2.2.2] octane skeleton were reported, ${ }^{18,19}$ while derivatives of this scaffold were used as templates for organic and asymmetric synthesis. ${ }^{20,21}$ In the $\beta$-amino acid series, bulky bicyclic side chains significantly reduce the accessible range of backbone torsion angles, but also strongly influence the spatial orientation of adjacent chemical groups and building blocks. It is noteworthy that bicyclic carbo-bridged scaffolds have been less studied than bicyclic-fused and hetero-bridged systems. Among them, the synthesis of bicyclo[2.2.1]heptane derivatives was the most reported along with few examples of the synthesis of 3-aminobicyclo[2.2.2]octane-2carboxylic acids and derivatives. ${ }^{22-24}$ In the following parts, we discuss our efforts towards the synthesis of the enantiopure $(R)$ - and $(S)$-1-aminobicyclo[2.2.2]octane-2-carboxylic acid $(\mathrm{ABOC}),{ }^{25}$ a highly constrained bicyclic $\beta$-amino acid bearing a bridgehead amino group as well as its diamine derivative, the 1,2-diaminobicyclo[2.2.2] octane (DABO). ${ }^{26}$ Our first motivation was to investigate the propensity of such building blocks to accommodate secondary structures in hybrid/mixed oligoamides ${ }^{1,3,27,28}$ and in oligoureas. ${ }^{2,29,30}$ Then, we assessed ABOC and DABO derivatives as effective enantioselective catalysts. ${ }^{4,31}$

\section{SYNTHESIS OF ENANTIOPURE ABOC AND DABO}

The route towards the original bicyclic $\beta$-amino acid ABOC involved an asymmetric Diels-Alder cycloaddition between the aminodiene $\mathbf{2}$ and the acrylate $\mathbf{1}$ equipped with the pantolactone-based chiral auxiliary (Scheme 1). ${ }^{25,32}$ The Diels-Alder cycloaddition between the dienophile $(S)-\mathbf{1}$ and the diene 2 under microwave irradiation in solvent-free conditions resulted in a mixture of the 
expected cycloadducts in good yield (91\%). Despite the moderate endo/exo selectivity (67\%), an excellent facial selectivity $(90 \%)$ allowed to isolate the $(S)$-1-aminobicyclo[2.2.2] octane-2carboxylic acid $(S)-3[(S)$-ABOC] after separation by column chromatography, cleavage of the chiral auxiliary and concomitant hydrogenation/hydrogenolysis. The $(R)$-ABOC $(R)-3$ enantiomer was obtained using the same procedure starting from the dienophile $(R)-\mathbf{1}$.

Scheme 1: Synthesis of H-(S)-ABOC-OH 3.

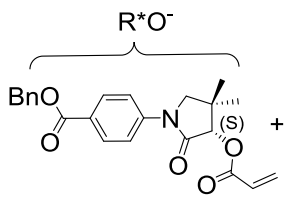

$(S)-1$

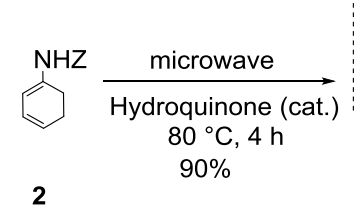

$$
\text { endc }
$$

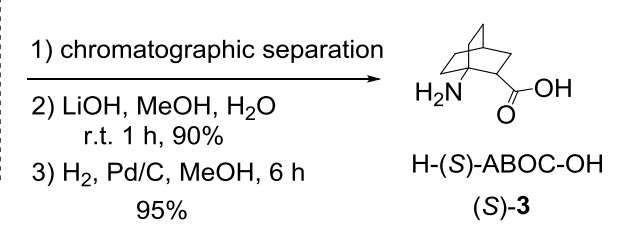

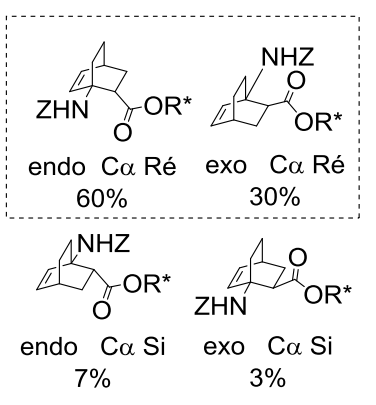

$3 \%$

We then explored the pathway towards the bridged bicyclic diamino derivative of ABOC, i.e. $(R)$ - and $(S)$-DABO 17 (Scheme 2). The high interest in chiral diamines and their derivatives lies on their occurrence in biologically active compounds as well as their importance in stereoselective catalytic processes in a broad variety of organic reactions. ${ }^{33}$ 
Scheme 2: Synthesis of enantiopure $(R) /(S)$-DABO 17.

\section{A. Non stereo-selective synthesis of saturated and unsaturated derivative Z-ABOC-OH}

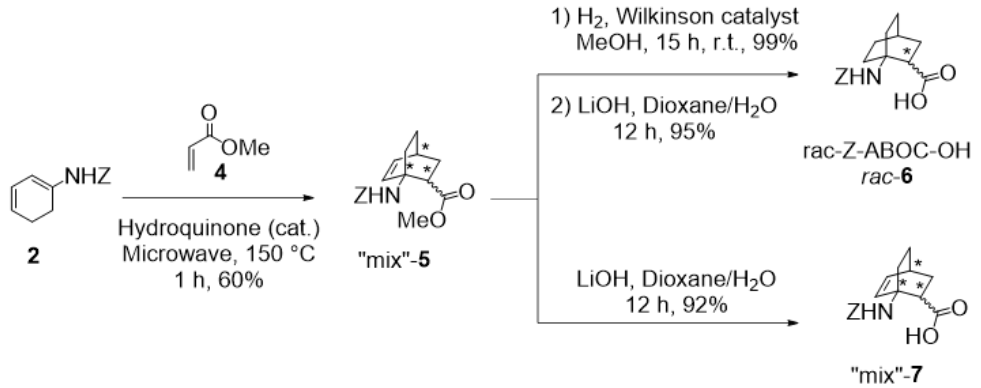

B. Investigation on Hofmann rearangement

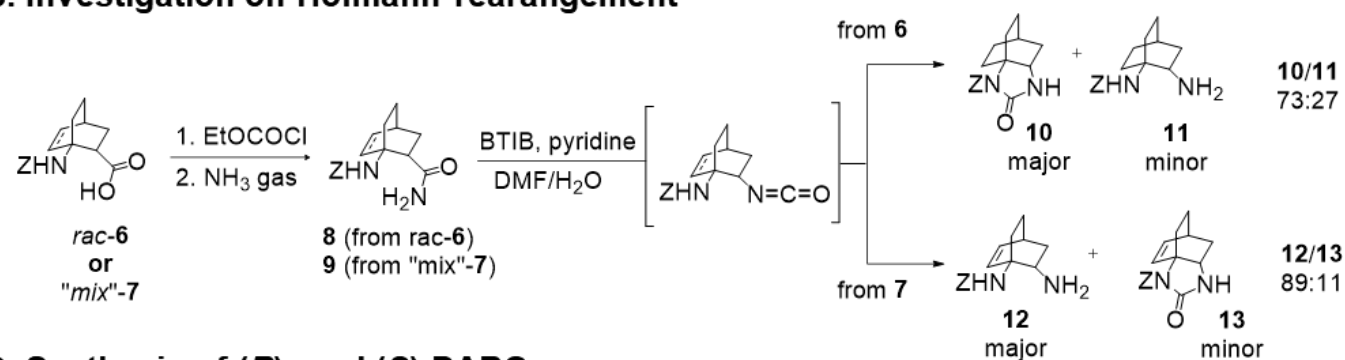

C. Synthesis of $(R)$ - and (S)-DABO

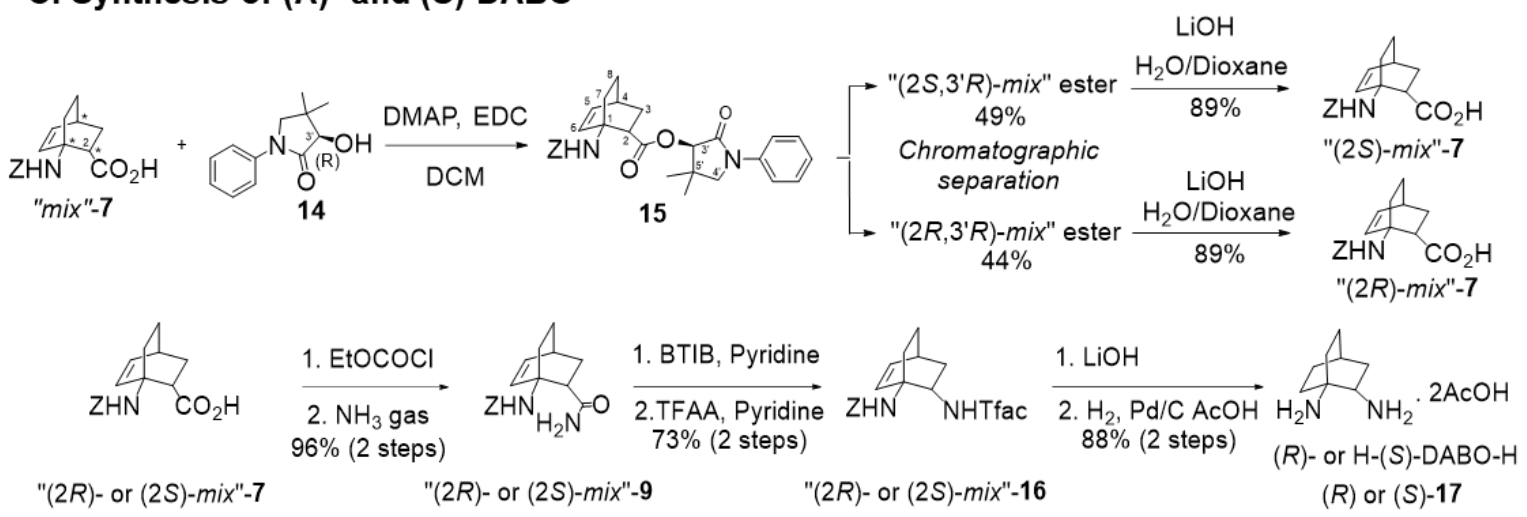

A straightforward strategy to synthesize the diamine DABO proceeded through the rearrangement of the carboxylic acid moiety of ABOC to an amine. Hofmann experimental conditions were explored, starting from the saturated rac-6 or unsaturated "mix"-7 derivatives of Z-ABOC-OH obtained using non-asymmetric Diels-Alder cycloaddition between the diene $\mathbf{2}$ and neat methyl acrylate 4 under microwave activation at $150^{\circ} \mathrm{C}$ (Scheme $2 \mathrm{~A}$.). ${ }^{26}$ The cycloadduct "mix"-5 was isolated in good yield but as a rather complex diastereomeric mixture due to both poor endo/exo and facial selectivity. Hydrogenation of the double bond in the presence of 
Wilkinson's catalyst followed by saponification of the methyl ester yielded the racemic Nbenzyloxycarbonyl protected ABOC [rac-Z-ABOC-OH, rac-6)] whereas direct saponification yielded "mix"-7. The Hofmann rearrangement of the bicyclo[2.2.2]oct-5-ene amide derivative 9 carried out under mild conditions $^{34}$ (Scheme 2B.) led mainly to the expected 1,2-diamine 12. By contrast, an unexpected divergent outcome investigated by $\mathrm{DFT}^{26}$ was observed under the same experimental conditions when using the saturated amide $\mathbf{8}$, affording mainly the corresponding cyclic urea $\mathbf{1 0}$ via an intramolecular trapping of the isocyanate intermediate by the carbamate nitrogen. After screening a few chiral alcohols to resolve the rather complex stereoisomeric mixture of unsaturated "mix"-7, pyrrolidinone $\mathbf{1 4}$ was identified as the most efficient auxiliary (Scheme 2C.). Thereby, the two pairs of diastereoisomers were obtained in good yield. Then, Hofmann rearrangement of each pair of the corresponding amide derivatives $\mathbf{9}$, followed by Nprotection of the free amine by a trifluoroacetamide group (Tfac) to ease the purification, saponification and hydrogenation/hydrogenolysis in $\mathrm{AcOH}$ yielded the enantiopure $(R)$ - and $(S)$ DABO 17 as a diacetate salt.

\section{HELICAL PEPTIDE/PEPTIDOMIMETIC FOLDAMERS}

We first studied the constrained $\mathrm{ABOC}$ building block as a folding element in peptide sequences (Figure 1 and 2). The carboxylic acid and amino groups of the ABOC residue were locked in a synclinal position that could potentially favour a turn within peptides. Reverse turns that are key structural motifs in biologically active peptides and proteins, have been often substituted by dipeptide mimics and to a lesser extent by $\beta$-amino acids. ${ }^{23,35-37}$ Therefore, we have evaluated the ability of the $\mathrm{ABOC}$ motif to induce a turn in peptide sequences. For that purpose, following the Boc standard peptide strategy in solution, we have synthesized two model peptides, incorporating the $\mathrm{ABOC}$ motif in central position and varying the capping groups, i.e. 
Z-Ala-(S)-ABOC-Phe-NHiPr 18 and iPrCO-Ala-(S)-ABOC-Phe-OCH 19. $^{1}$ Their structures were studied in solution by circular dichroism (CD), Fourier transform infrared (FTIR) and nuclear magnetic resonance (NMR) spectroscopies, and in the solid-state by X-ray diffraction (XRD). These techniques were combined with molecular dynamics (MD) and DFT calculations. We showed that $\mathrm{ABOC}$ was able to induce a reverse turn both in organic solvents and in the solid-state. The crystal structure of $\mathbf{1 8}$ showed $C_{9}$ and $C_{11}$ hydrogen bonds (Figure 1A). Thereby, these promising results have encouraged us to extend our investigations in the field of peptide foldamers. 


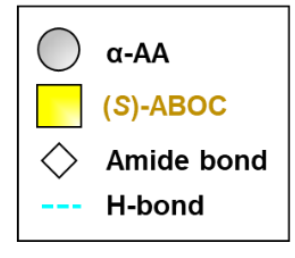

$\mathrm{R}=\mathrm{OBg}, \beta-\mathrm{Ala}-\mathrm{OBg}$, $\mathrm{OMe}, \mathrm{NHiPr}$ $\mathrm{R}^{\prime}=\mathrm{Boc}, \mathrm{iPr}, \mathrm{OBn}$

B

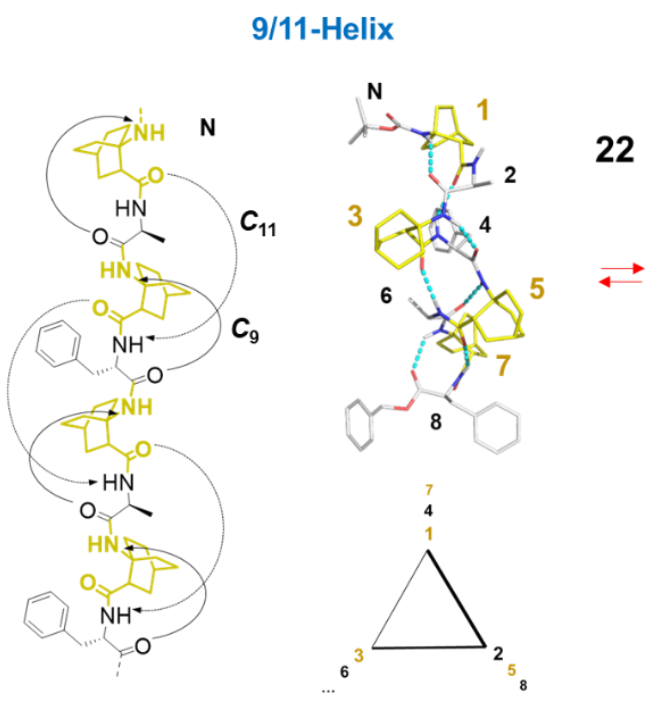

12/14/14-Helix

C

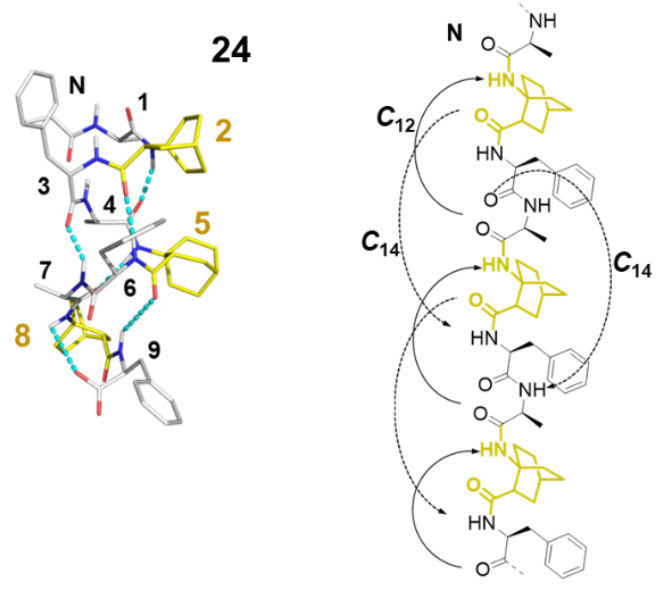

(S)-ABOC

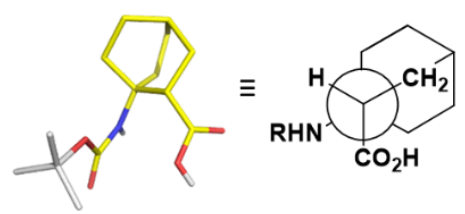

22

\section{A (S)-ABOC as reverse-turn}

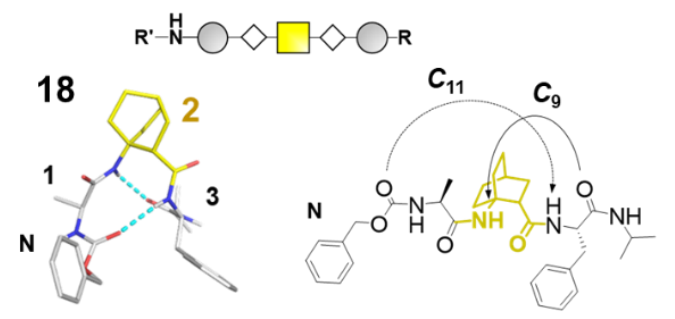

\section{Hybrid-oligomers}
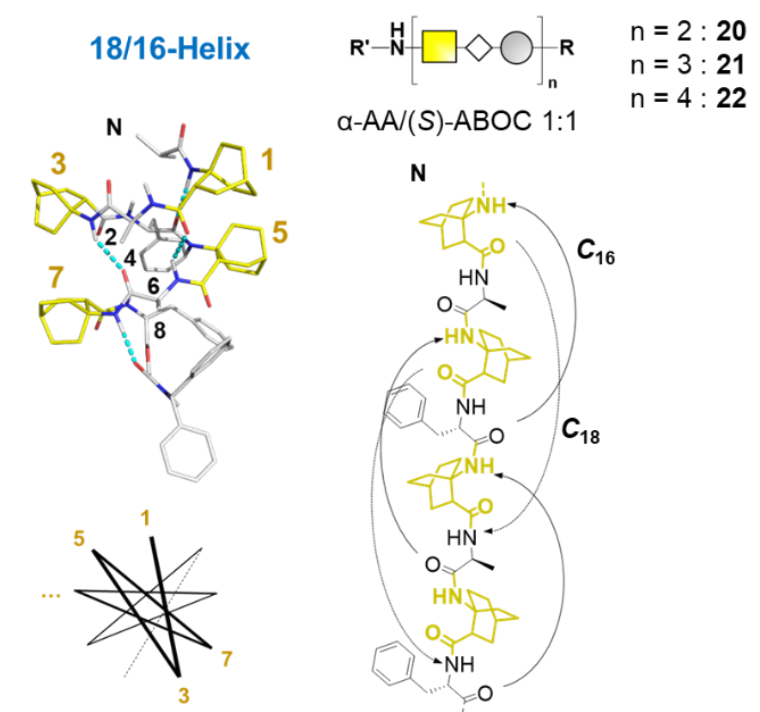

$n=4: 22$

A
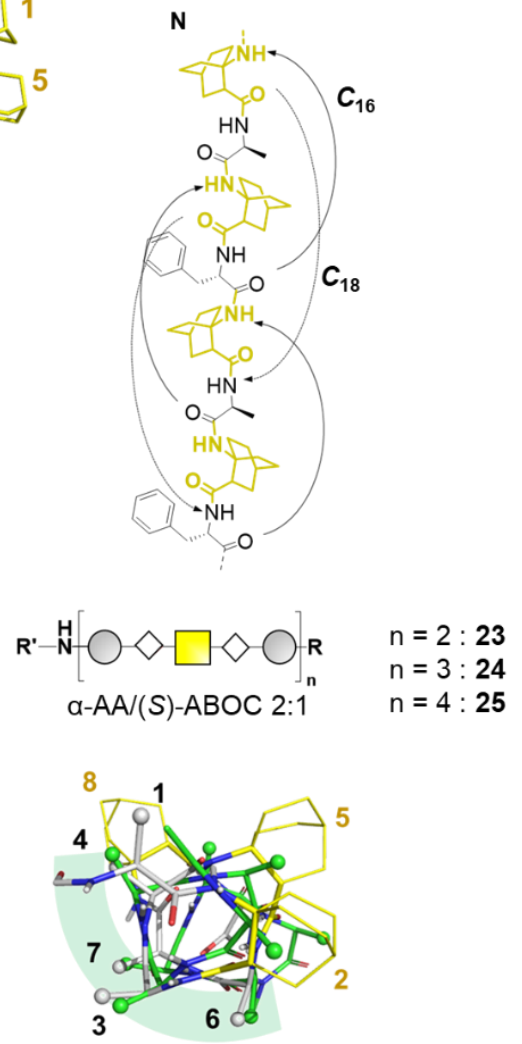

Figure 1: Hybrid oligoamide structures composed of $(S)$-ABOC and $\alpha$-AA.

We focused on the use of $\mathrm{ABOC}$ motif in heterogeneous backbone systems that have significantly enlarged the diversity of attainable molecular architectures. ${ }^{38}$ In this context, we 
synthesized hybrid oligomers of various lengths by combining $\mathrm{ABOC}$ and proteinogenic $\alpha$ amino acids $(\alpha-\mathrm{AAs})$, first with a 1:1 alternation of $\alpha-\mathrm{AA} /(S)-\mathrm{ABOC}$ residues, and then by decreasing the $\mathrm{ABOC}$ content, with 2:1 and 3:1 alternations (Figure 1B and $1 \mathrm{C}$ ). ${ }^{3,27}$ Although the 1:1 $\alpha$-AA/(S)-ABOC crystal structure showed a 9/11-helix consistently with our previous model tripeptide, we detected a chain-length-dependent conformational polymorphism between the 9/11- and a wider 18/16-helix in solution (Figure 1B). ${ }^{27}$ The tetramer 20 adopted a 9/11-helix like in the solid-state, while the hexamer 21 structure was in equilibrium between the 9/11- and the 18/16-helices, and finally only typical NOE correlations of the 18/16-helix could be detected for the octamer 22. We hypothesized that the constraints imposed by the crystal lattice and the packing interactions might favour the $9 / 11$-fold in the solid-state. Interestingly, the interconversion between the two helices in solution involved a unique rotation of about $90^{\circ}$ of the $\alpha$-AA $\phi$ angle, while the other backbone dihedral angle values remained nearly unchanged. Conformational polymorphism between a 11- and a 14/15-helix was previously reported by Gellmann and co-workers for oligomers alternating $\alpha$-AAs and trans-2-aminocyclopentane carboxylic acids (ACPCs). ${ }^{39}$ On the other side, the 2:1 $\alpha$-AA/(S)-ABOC sequences 23-25 adopted a single original 12/14/14-helix in solution stabilized by hydrogen bonds with opposite directionality, forming intramolecular 12- and 14-membered pseudocycles (Figure 1C). ${ }^{3}$ The geometry of hexamer $\mathbf{2 4}$ was particularly attractive since the orientation of $\alpha$-AA side chains matched rather well with those in the canonical $\alpha$-helix. Finally, attempts to further dilute the ABOC residue among $\alpha$-amino acids failed to give rise to stable architectures, e.g. short 1:3 $\alpha$ AA/(S)-ABOC oligomers did not fold (unpublished results).

In parallel, we investigated ABOC-based $\beta$-peptides. In particular, we focused on $(S)$-ABOC homo-oligomers and oligomers with a 1:1 alternation of $\beta^{3}$-homoamino acids $\left(\beta^{3}\right.$-hAAs) and $(S)$ - 
$\mathrm{ABOCs}$, i.e. $\beta^{3}$-hAA $/(S)$-ABOC mixed oligomers (Figure 2$) .{ }^{28} \beta$-peptide helices could adopt various shapes including the $10-$, the $10 / 12-$, the 12 - and the 14 -helices, depending on the $\beta$ amino acid substitution patterns. ${ }^{40}$ Among them, the 14 -helix composed of acyclic $\beta^{3}$-hAAs was extensively studied for therapeutic purposes including protein-protein interaction inhibitors and drug delivery compounds. ${ }^{41,42}$ Besides, various homo-oligomers composed of cyclic motifs have been successfully synthesized and reported in the literature, affording an important contribution to the field of foldamers. ${ }^{40}$ In our case, despite great efforts to obtain homo-ABOC oligomers and the successful syntheses of various homo-oligomers composed of cyclic motifs reported in the literature, we failed to elongate the poly-ABOC chain beyond two units. Indeed, the dimer $\mathbf{2 6}$ crystal structure showed a flat ribbon structure devoid of hydrogen bonds, both monomers sharing similar torsion angle values, i.e. $\phi=59 \pm 2^{\circ}, \theta=45 \pm 2^{\circ}$ and $\psi=-111 \pm 13^{\circ}$ (unpublished results, Figure 2A). Both the rigidity and the steric hindrance of ABOC prevented the required approach of the third residue for the formation of a subsequent amide bond. In addition, the flat 'N-shape' adopted by consecutive ABOC residues in compound $\mathbf{2 6}$ might be incompatible with helical structures. 


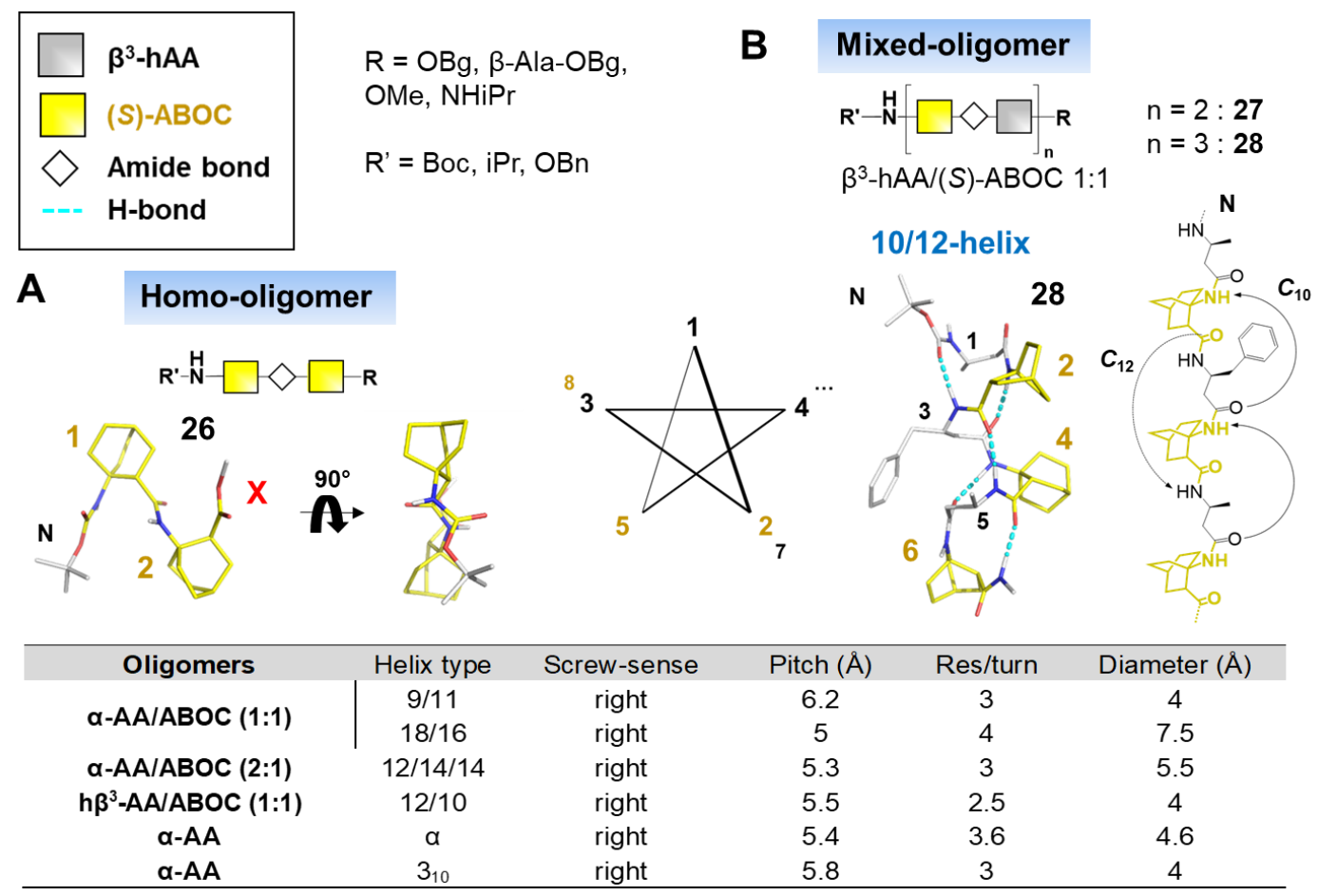

Figure 2: $\beta$-peptide structures composed of $(S)$-ABOCs and $\beta^{3}$-hAAs. Comparison of the main helical parameters for the 9/11-, 18/16-, 12/14/14, and naturally occurring $\alpha$ - and $3{ }_{10}$-helices.

These results prompted us to study mixed oligomers alternating $\beta^{3}$-hAAs and $(S)$-ABOCs in a $1: 1$ pattern. $^{28}$ Incorporation of commercially available acyclic substituted $\beta$ - homologated proteinogenic amino acids bearing a broad range of functional groups would allow the development of versatile oligomers for applications. We successfully synthesized $1: 1 \beta^{3}$ hAA/ABOC oligomers 27 and $\mathbf{2 8}$ of various lengths. Hexamer 28 adopted a stable 12/10-Helix conformation in various organic solvents (Figure $2 \mathrm{~B}$ ). The mixed hydrogen bonds forming $C_{10}$ and $C_{12}$ pseudo rings were in opposite directions along the helix axis, resulting in a smaller macrodipole generally inducing a weaker stability in polar solvent compared to unidirectional helices. However, the real plus of the $\beta^{3}$-hAA/ABOC helices was that their stability was not solvent-dependent while other building block combinations underwent partial or total loss of 
structure in polar solvents. ${ }^{43,44}$ We showed by DFT calculations that the strength of the $C_{10}$ hydrogen bonds was significantly higher than in acyclic $\beta^{3}-\mathrm{hAA} / \beta^{2}-\mathrm{hAA}$ model oligomers. The $\mathrm{NH}$ and $\mathrm{CO}$ vectors were locked in optimal directions to establish strong $C_{10}$ hydrogen bonds. Moreover, the amino group at the $\mathrm{ABOC}$ bridgehead involved in the $C_{10}$ was protected from the solvent.

\section{HELICAL OLIGOUREA FOLDAMERS}

In the meantime, we studied the effect of incorporation of bicyclo[2.2.2]octane rings in oligoureas. $^{2,29,30}$ Guichard and co-workers have shown earlier that oligoureas derived from acyclic $\beta^{3}$-hAAs, i.e. composed of (S)-2-amino alkyl carbamoyl (AAC) residues, adopt typical 12/14-helices stabilized by bifurcated hydrogen bonds (Figure 3B and 3D). ${ }^{45}$ In this context, the perspective to develop highly stable helices incorporating a few motifs combining both constrained bicyclic motifs and bifurcated hydrogen bonds stabilization brought by urea linkages, have stimulated these researches. Moreover, the longer urea link could significantly reduce the steric hindrance between bicycles and might allow the synthesis of homo-bicyclic amino carbamoyl oligomers, i.e. BAC oligoureas.

Thus, we have first successfully synthesized short $(S)$-BAC oligomers $29, \mathbf{3 0}$ and $\mathbf{3 1}$ by stepwise assembly using the Boc standard strategy and the succinimidyl carbamate derivative of ABOC [Boc-(S)-BAC-OSu] (Figure 3A). ${ }^{2}(S)$-BAC oligomers adopted robust right-handed 12/14-helices both in solution and in the solid-state. Topological parameters were closed to those of the oligourea canonical helix with 2.5 residues per turn, a pitch of $5.1 \AA$, although the $\phi$ and $\theta_{2}$ torsion angles values were swapped, i.e. $\phi=63 \pm 6^{\circ}, \theta_{1}=54 \pm 9^{\circ}$, and $\theta_{2}=-109 \pm 21^{\circ}$ in the crystal structures (Figure 3C, left panel and 3D). It was noteworthy that only two BAC residues 
already initiated the 12/14-helix conformation and no cis-trans urea bond isomerization was detected in solution by NMR. Moreover, CD spectra of hexamers showed that the homo-(S)BAC oligourea 31 helix displayed a greater stability than the acyclic oligourea $\mathbf{3 2}$ helix (Figure 3E). Indeed, both compounds exhibited similar signatures with strong positive maxima around $204 \mathrm{~nm}$ but 31 showed a higher intensity.

A

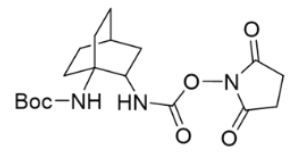

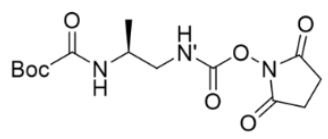

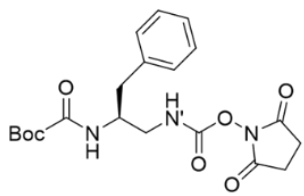

Boc- $(S / R)$ BAC-OS

Boc-APC-OSu

Boc-APPC-OSU

B

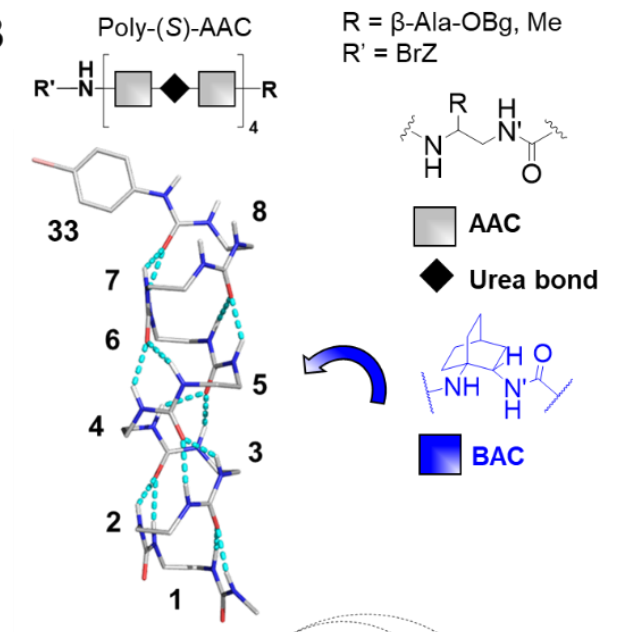

D Poly-(S)-AAC

Poly-(S)-BAC

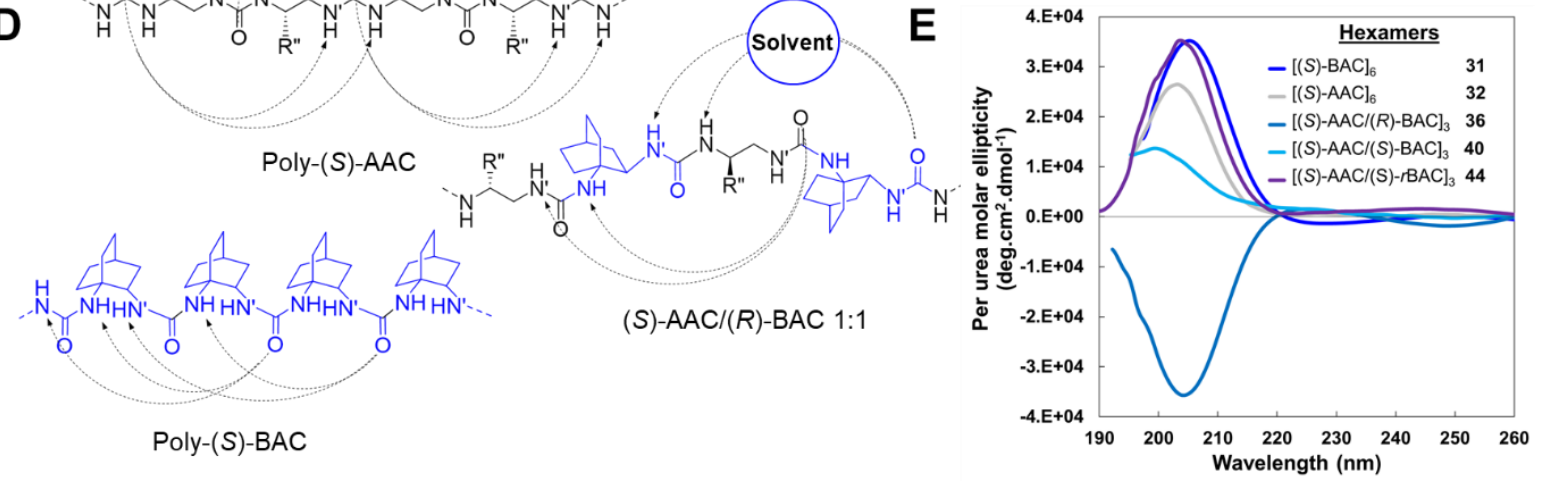

C Poly-(S)-BAC $\mathrm{n}=1: 29$ $R^{\prime}-H^{H}\left[\begin{array}{cc}n=1: 29 \\ R & n=2: 30 \\ n & n=3: 31\end{array}\right.$

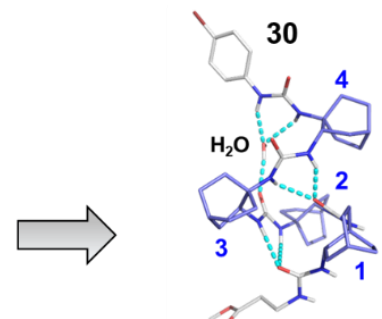

(S)-AAC/(S)-BAC 1:1 $n=1: 38$ $\left.R^{\prime}-\mathrm{H}[\square \longrightarrow]_{n}\right]_{n} \begin{aligned} & n=2: 39 \\ & n=3: 40 \\ & n=4: 41\end{aligned}$ Unfolded oligomers $n=4: 41$
(S)-AAC/(R)-BAC 1:1

$\mathrm{n}=1: \mathbf{3 4}$

$\mathrm{n}=2: 35$ $\mathrm{n}=3: \mathbf{3 6}$ $n=4: 37$
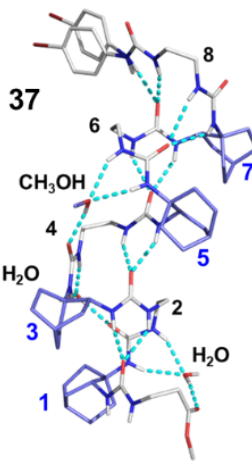

Figure 3: Formula of succinimidyl carbamate derivatives. Canonical acyclic $[(S)-\mathrm{AAC}]_{8}$ oligourea 33 (ccdc750017) $)^{45}$ and BAC-containing oligoureas: poly-(S)-BAC tetramer 30 and $(S)$ - 
$\mathrm{AAC} /(R)$-BAC octamer 37 crystal structures. Comparison of the hydrogen bond networks and $\mathrm{CD}$ profiles of the various oligourea foldamers.

The next step was to incorporate specific side chains to lead to functional platforms while taking advantage of the bicycle constraints. For that purpose, the ( $S$ or $R$ )-BAC residues were mixed with $(S)-\beta^{3}-\mathrm{hAla}$ and $(S)-\beta^{3}-\mathrm{hPhe}$, converted into their corresponding $\mathrm{N}-(2-$ aminopropyl)carbamoyl (APC) and N-(2-amino-3-phenylpropyl)carbamoyl (APPC) units respectively, in a 1:1 pattern using the Boc standard strategy (Figure 3C, right panel) ${ }^{29}$ The succinimidyl carbamate $(\mathrm{OSu})$ derivatives Boc- $(S$ or $R)$-BAC-OSu, Boc- $(S)$-APC-OSu and Boc$(S)$-APPC-OSu (Figure 3A) were prepared from Boc- $(S$ or $R)$-ABOC-OH, Boc- $(S)-\beta^{3}$-hAla-OH, and Boc- $(S)-\beta^{3}$-hPhe-OH, respectively. We synthesized oligoureas of various lengths $\mathbf{3 4 - 3 7}$ for the $(R)$-BAC/(S)-AAC and 38-41 for the $(S)$-BAC/(S)-AAC sequences. While the $(R)$-BAC/(S)AAC hexamer 36 displayed the characteristic oligourea helix CD signature with a strong negative minimum around $204 \mathrm{~nm}$ (indicative of a left-handed screw sense), the CD signal of the $(S)$-BAC/(S)-AAC hexamer 40 was atypical and weak, around 10,000 deg.cm².dmol ${ }^{-1}$ (Figure $3 \mathrm{E})$. Moreover, the $\mathrm{CD}$ signal of the $(S)$-BAC/(S)-AAC sequences did not increase with the oligomer's length as typically observed for folded oligomers. ${ }^{29}$

NMR studies confirmed that homochiral oligomers were unfolded, while the heterochiral sequences adopted left-handed 12/14-helices in solution. The crystal structure of the $(R)$ BAC/(S)-AAC octamer 37 helix was obtained (Figure 3C, right panel). Nevertheless, the helix axis was significantly bent by the presence of solvent molecules $\left(\mathrm{H}_{2} \mathrm{O}\right.$ and $\left.\mathrm{CH}_{3} \mathrm{OH}\right)$ intercalated into a hydrogen bond network, acting as bridges between urea amide protons and carbonyl groups (Figure 3D). A close inspection of the $(R)-\mathrm{BAC} /(S)$-AAC structures revealed that the AAC side chains were projected in inadequate intermediate positions generating steric clashes 
with the adjacent backbone carbonyls. The steric hindrance in the heterochiral helix was partially offset by the solvent molecule's insertion. In homochiral oligoureas, the AAC side chains would be in the axial orientations and would prevent the oligourea helix folding. Starting from these results, we anticipated that a simple reversal of the bicycle swapping the bridgehead position, and the 2-position within the final oligoureas, should lead to stable helices with AAC side chains in optimal lateral orientation. ${ }^{30}$ Indeed, the reverse bicyclic amino carbamoyl unit $(r \mathrm{BAC})$ shared similar torsion angle values with the acyclic AAC residues in the canonical oligourea helix, and the $(S)-r \mathrm{BAC} /(S)$-AAC oligoureas would ideally fold with AAC substituents in lateral positions.
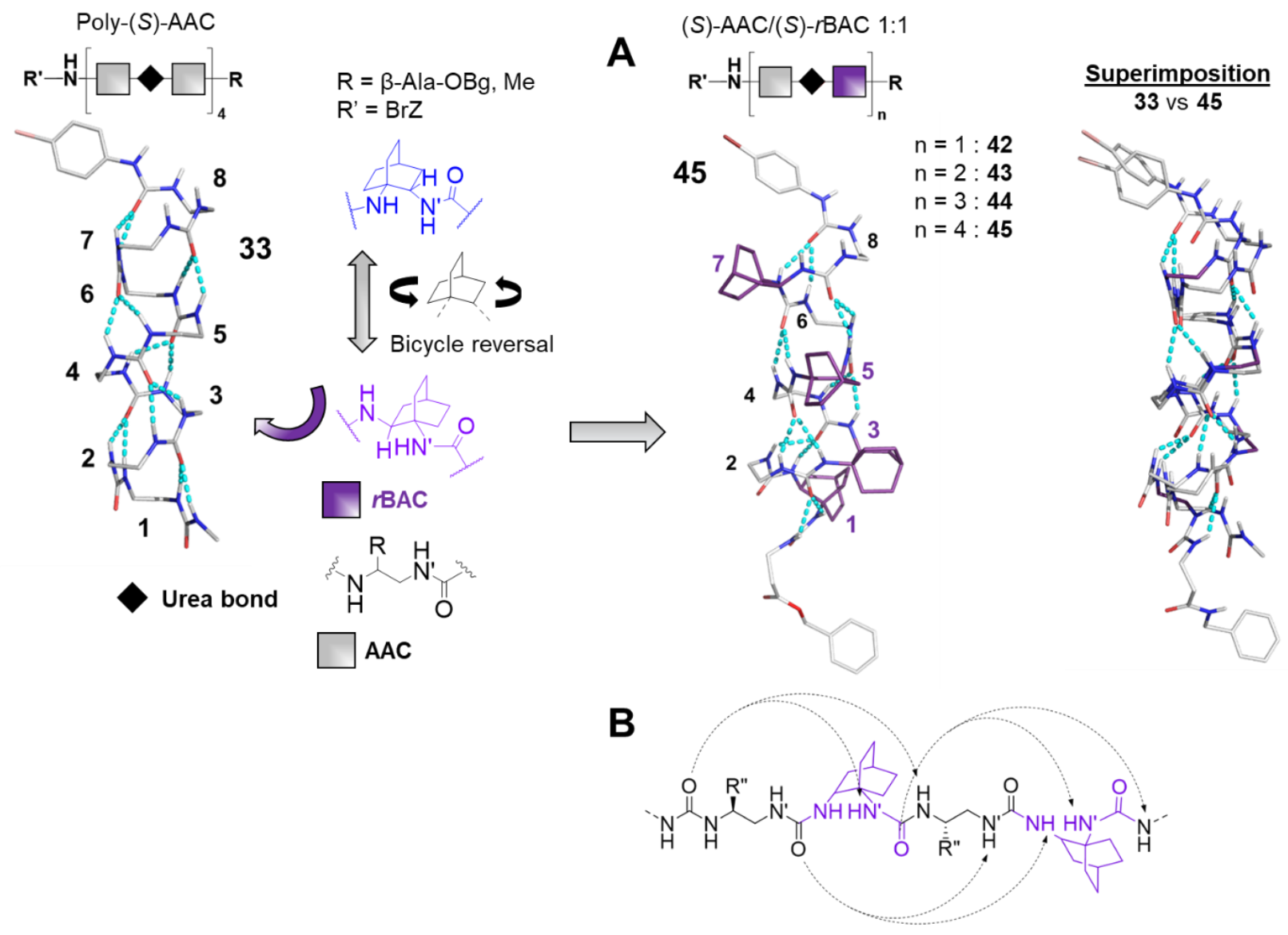

Figure 4: Acyclic $[(S)-\mathrm{AAC}]_{8}$ oligourea 33 and $(S)-\mathrm{AAC} /(S)-r \mathrm{BAC}$ octamer 45 crystal structures. 
The synthesis of the mixed oligoureas 42-45 required the use of the chiral $(S)-1,2-$ diaminobicyclo[2.2.2] octane motif $[(S)-\mathrm{DABO}]$ previously developed in our group (Scheme 2$){ }^{26}$ The first coupling was performed by adding an equimolar amount of $\mathrm{H}-(S)$-DABO-Boc to the succinimidyl carbamate of H- $\beta-A l a-O B n$ (Suc-OCO- $\beta-A l a-O B n$ ) in the presence of N,Ndiisopropylethylamine (DIEA). The peptide chain was elongated using a Boc standard strategy in solution. Freshly activated H-(S)-DABO-Boc with N,N'-disuccinimidyl carbonate (DSC), leading to Suc-OCO- $(S)$-DABO-Boc, was used to correctly incorporate the $(S)$-rBAC residue and reduce formation of the cyclic biuret by-product by limiting the activation time, and by repeating the coupling step until completion of the reaction. The $\mathrm{CD}$ spectra of $(S)-\mathrm{AAC} /(S)$ rBAC eligemers hexamer 44 displayed the typical oligourea 12/14-helix signature (Figure 3E). NMR and crystal structures showed that the $(S)-\mathrm{AAC} /(S)-r \mathrm{BAC}$ oligomers adopted the typical right-handed 12/14-helix both in solution and in the solid-state, which was well-superimposed with the canonical oligourea helix composed of acyclic $\beta^{3}$-hAA derivatives (Figure 4A). AAC side chains were ideally oriented in lateral position, perpendicularly to the helix axis and this latter was perfectly straight. Interestingly, both the homo- $(S)-\mathrm{BAC}$ and $(S)-\mathrm{AAC} /(S)-r \mathrm{BAC}$ oligomers of same length shared comparable CD signal intensities, indicating a similar helix stability despite two times less bicyclic constrained motifs in the mixed oligourea (Figure 3E).

\section{ASYMMETRIC CATALYZED REACTIONS}

Asymmetric catalysis relies essentially on the ability of a chiral catalyst to interact with reaction substrates, and to exclusively stabilize the transition state towards the formation of a single product stereoisomer product. For that purpose, geometric constraints are key features of chiral catalysts to tune their steric properties and to control occupation of the three-dimensional chemical space. These properties are found in living systems where complex asymmetric 
biochemical reactions are achieved by enzymes with well-defined three-dimensional structures in thoroughly organized active sites.

In this context, the bicyclo[2.2.2]octane structure was applied to the design of novel peptide catalysts for asymmetric synthesis. Short peptides have received increasing attention in asymmetric organo-catalysis of diverse reactions as they possess a high degree of structural diversity and complexity, and are rather simple to synthesize. ${ }^{46}$ Over the past 20 years, many highly efficient peptide catalysts have been developed to promote the asymmetric aldol reaction, some of them exhibiting very high enantiomeric excesses and low catalyst loadings. ${ }^{47}$ Nevertheless, only a few examples involve $\beta$-amino acids. Thus, this reaction is particularly attractive to evaluate the impact of the constrained ABOC $\beta$-amino acids in catalysis. Therefore, a variety of $\alpha, \beta$-peptides 46-60 containing proline and $\mathrm{ABOC}$ have been synthesized in solution using typical Boc strategies. They were tested for their catalytic properties in the asymmetric aldol reaction between $p$-nitrobenzaldehyde and acetone (Figure 5A). Dipeptides 46-49 were less effective than tripeptides and for these latter, the rate and stereoselectivity of the reaction was highly dependent on both the absolute configuration of the $\mathrm{ABOC}$ and on the nature of the $\mathrm{C}$ terminal amino acid. As a general result, the heterochiral sequences gave better results than homochiral sequences, and the tripeptide 59, i.e. H-Pro- $(R)-\mathrm{ABOC}-\mathrm{Asp}-\mathrm{OCH}_{3}$, was the most effective. The absence of a third chiral centre (peptides 50-53) or of a carboxylic acid function (peptide 58), as well as the presence of a second carboxylic acid function on the C-terminal amino acid (peptides 54-55), led to a lower enantioselectivity in both homo- and heterochiral sequences. 


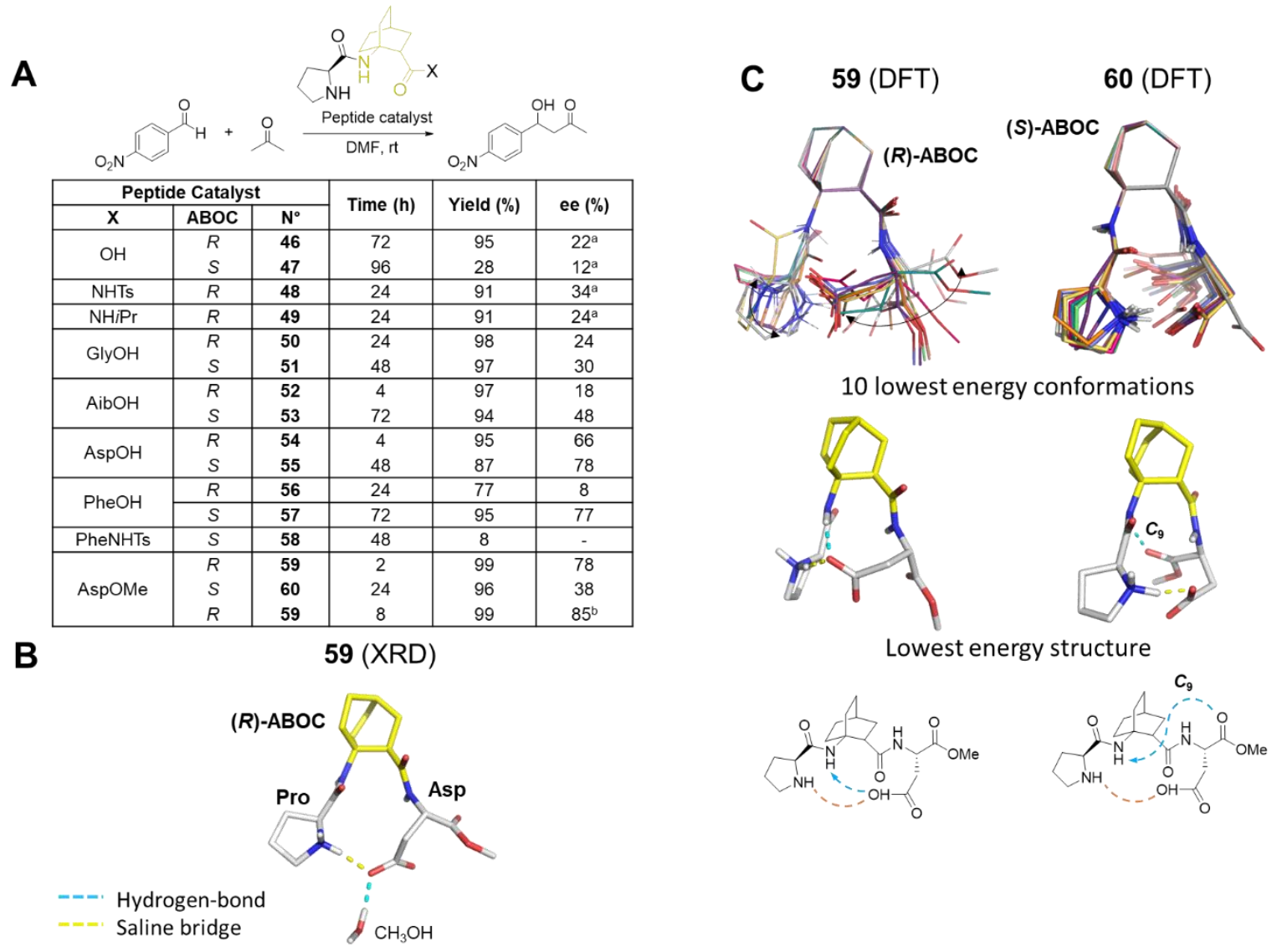

All reactions were carried out at $25^{\circ} \mathrm{C}$ using $0.05 \mathrm{mmol}$ of $p$-nitrobenzaldehyde and $20 \mathrm{~mol} \%$ of catalyst in $0.9 \mathrm{ml}$ of acetone:DMF (1:2). Conversion and enantioselectivity of aldol products were determined by analytical chiral HPLC analysis on a chiralpak AS-H column, detection at $270 \mathrm{~nm}$. The absolute configuration of the major enantiomer was assigned by comparison with literature data. ${ }^{\mathrm{a}}$ The four examples involving dipeptide catalyst yielded the aldol product of absolute configuration $(R) .{ }^{b}$ Reaction carried out at the optimal temperature of $-20^{\circ} \mathrm{C}$.

Figure 5: ABOC containing peptides as organocatalyst in the asymmetric aldol reaction and comparison of the structures of tripeptides 59 and $\mathbf{6 0 .}$

The best peptide catalyst $\mathbf{5 9}$ was used in the aldol reaction between diverse benzaldehyde and acetone under the optimised experimental conditions providing high yields and good enantioselectivities (up to $88 \%$ ) in the presence of only $5 \mathrm{~mol} \%$ catalyst. Given the important efficiency gap between heterochiral and homochiral catalysts, we studied the impact of the $\mathrm{ABOC}$ absolute configuration on the conformations of tripeptide $\mathbf{5 9}$ and $\mathbf{6 0}$ conformations. The 
crystal structure of heterochiral peptide $\mathbf{5 9}$ showed a turn structure with a salt-bridge between the amine function and the carboxylic acid both involved in the catalytic mechanism (Figure 5B.). The close proximity between the two reactive functions was consistent with effective aldol reactions with high degrees of stereoselectivity. Unfortunately, we could not obtain suitable monocrystals of peptide $\mathbf{6 0}$, therefore we compared the structures of $\mathbf{5 9}$ and $\mathbf{6 0}$ using DFT calculations (Figure 5C). Both tripeptides adopted turn structures driven by the ABOC residue, most of the structures exhibited a salt-bridge between the secondary amine and the carboxylic acid. Additionally, a hydrogen bond between the $\mathrm{ABOC} \mathrm{HN}$ and the carboxylate group was observed in structures of $\mathbf{5 9}$ (Figure 5B, left panel), while conformations of the homochiral peptide $\mathbf{6 0}$ were further stabilized by a $C_{9}$ pseudoring, according to the iPrCO-Ala- $(S)$-ABOCPhe- $\mathrm{OCH}_{3}$ model tripeptide crystal structure previously described (Figure 5B, right panel). ${ }^{1}$ Like previous reports, ${ }^{15,48}$ we noticed the stabilization of a turn maintaining both the amine and carboxylic acid functions in direct vicinity that could correlate to efficient catalytic activities. Nevertheless, the difference of rate and stereoselectivity between heterochiral and homochiral peptides was difficult to rationalize. DFT calculations showed an enhanced flexibility for the heterochiral compound $\mathbf{5 9}$ compared to its homochiral analogue $\mathbf{6 0}$, suggesting that a greater flexibility could guarantee a high adaptability, while $\mathbf{6 0}$ might be trapped in suboptimal conformations. This study, although not improving precedent reported results, provided valuable information about the relationship between conformation and efficiency of these catalysts that could be extremely useful in the development of future catalytic systems.

Capitalising on these results, we pursued by designing ligands based on the DABO residue to catalyse another well-documented reaction, the copper-catalysed asymmetric Henry reaction. Chiral 1,2-diamines are precursors of privileged chiral ligands such as salen-type 
ligands and bidentate ligands that play a key role in transition metal-based catalytic systems. Usually based on constrained cyclic diamine scaffolds, these ligands often possess $\mathrm{C}_{2}$ symmetrical structures where their symmetry axis reduces the number of possible transition states and reaction pathways, for a catalysed reaction. ${ }^{49,50} \mathrm{C}_{1}$-symmetric scaffolds are less commonly used, although they have proven to be effective in asymmetric transformations. ${ }^{51}$ The copper-catalysed asymmetric Henry reaction is achieved with very high enantiomeric excesses typically using $\mathrm{C}_{2}$-symmetric ligands such as bisoxazolines. ${ }^{52}$ However, very few examples of non-symmetric ligands have been reported. In this context, the evaluation of DABO as chiral ligands was particularly interesting. Indeed, DABO provided such a $\mathrm{C}_{1}$-symmetric structure and was used as a precursor to synthesize bidentate and tetradentate ligands using classical procedures for reductive amination of diverse aldehydes. These ligands were utilised in the copper-catalysed asymmetric Henry reaction between $p$-nitrobenzaldehyde and nitromethane (Figure 6). If the use of salen-type tetradentate ligands $\mathbf{6 1}$ and $\mathbf{6 2}$ resulted in a very slow reaction with modest enantioselectivity, bidentate ligands 63-70 substantially accelerated the reaction and provide up to $80 \%$ enantiomeric excesses.

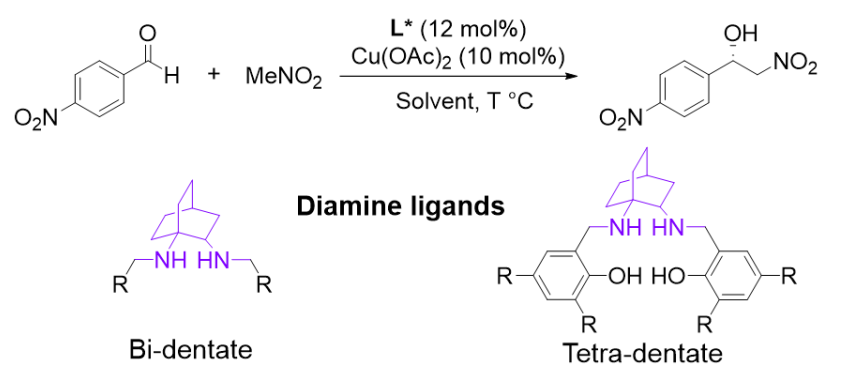

\begin{tabular}{|c|c|c|c|c|}
\hline Ligands & $\mathbf{R}$ & Time (h) & Yield (\%) & ee (\%) \\
\hline Tetra- & t-Bu (61) & 168 & 88 & $60^{\mathrm{a}}$ \\
dentate & $\mathrm{H} \mathrm{(62)}$ & 144 & 78 & $5^{\mathrm{a}}$ \\
\hline & p-Cl-Ph (63) & 60 & 78 & $64^{\mathrm{b}}$ \\
& m-Cl-Ph (64) & 48 & 50 & $56^{\mathrm{b}}$ \\
& o-Cl-Ph (65) & 7 & 66 & $50^{\mathrm{b}}$ \\
Bi- & 1-naphtyl (66) & 72 & 95 & $80^{\mathrm{b}}$ \\
dentate & 2-napthyl (67) & 60 & 74 & $64^{\mathrm{b}}$ \\
& Anthracyl (68) & 48 & 66 & $30^{\mathrm{b}}$ \\
& o-OMe-Ph (69) & 240 & 72 & $64^{\mathrm{b}}$ \\
& Furyl (70) & 12 & 77 & $72^{\mathrm{b}}$ \\
\hline
\end{tabular}

Yields are isolated yields after column chromatography. Enantioselectivity of nitro-aldol products were determined by analytical chiral HPLC analysis of the crude on a chiralpak OD-H column, detection at $214 \mathrm{~nm} .{ }^{a}$ Reaction performed in toluene at room temperature, ${ }^{b}$ reaction performed in isopropanol at $0{ }^{\circ} \mathrm{C},{ }^{\mathrm{c}}$ incomplete conversion. 
Figure 6. Evaluation of diamine ligands $\left(\mathrm{L}^{*}\right)$ derived from $\mathrm{DABO}$ in copper-catalysed asymmetric Henry reaction

Ligands with diverse aromatic substituents were tested to probe the effect of bulkiness and electronic properties. The ligand $\mathbf{6 6}$ with 1-naphtyl substituents on the amine groups provided the best yields and enantioselectivity. A broad range of Henry's substrates were tested under these experimental conditions, and moderate to very good yields as well as good enantioselectivities were obtained using both aromatic and aliphatic aldehydes (Figure 7A).

In an attempt to rationalize asymmetric induction in this reaction, theoretical studies of the transition structures were carried out (Figure 7B). The transition state of the reaction was considered to be composed of the ligand-copper complex with one acetate group, the $4 p$ nitrobenzaldehyde and the nitronate anion.

A

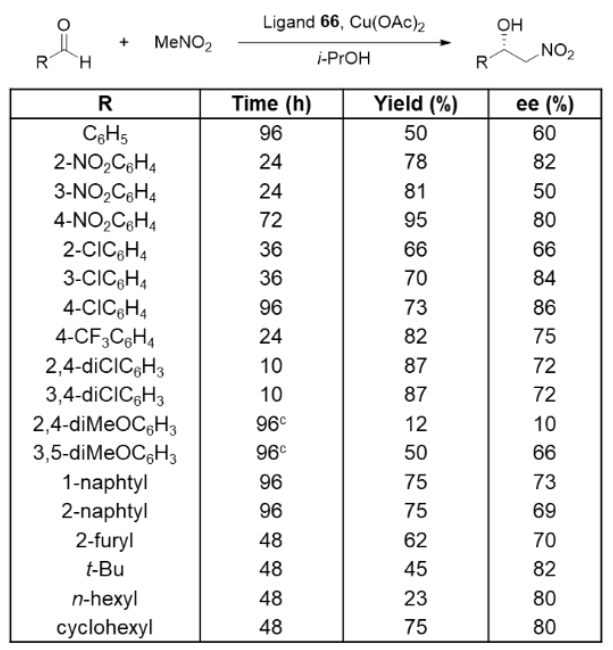

B

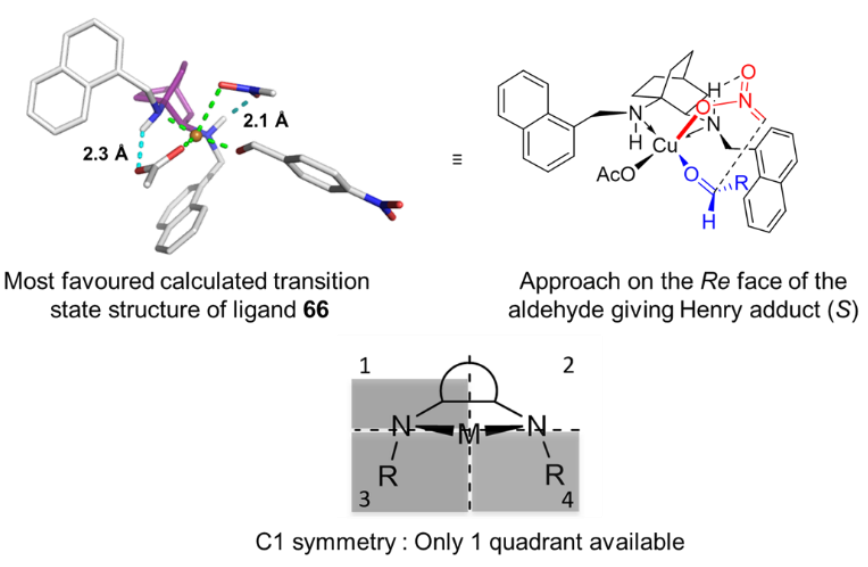

Figure 7: Scope of the reaction using the most efficient ligand $\mathbf{6 6}$ and rational for the stereoselectivity and the major obtained enantiomer. 
Free energies and energy barriers were obtained for a few transition-state structures, and calculations were optimized to obtain the most favoured calculated transition state. It exhibited an approach of the nitronate from the $R e$ face of the aldehyde leading to a product with $S$ configuration as observed experimentally. It is worth noting that the $\mathrm{C}_{1}$-symmetry of the ligand allows to hinder a large area in the surrounding of the copper atom making a single quadrant available for the substrates to react, in this favoured transition state structure.

\section{SUMMARY AND OUTLOOK}

Topological restraints encoded in 1-aminobicyclo[2.2.2] octane-2-carboxylic acid were successfully used as driving forces to guide the folding of helical architectures when mixed with naturally-occurring $\alpha$-AAs and commonly used $\beta^{3}$-hAAs in peptide foldamers. The bulky bicyclo[2.2.2] octane induced a high steric pressure, which locked the ABOC backbone torsion angle values and affected the spatial arrangement of adjacent and remote residues. It provided robust helical shapes for only short sequences with limited effects of external factors such as temperature and solvent, thus ensuring the stability of the oligomers structure, while the $\alpha$ - and $\beta^{3}$-hAA brought versatile side chains. The 9/11-, 18/16-, 12/14/14- and 10/12-helices exhibited various topological parameters (pitch, residue per turn, diameters, etc.) and thus rather different side chains positioning patterns. On the other side, all these helices share common features, which are intrinsically related to the chemical nature and the resulting preorganization of the ABOC monomer. In the whole structures, the $(S)$-ABOC residue exhibited backbone torsion angle values around $\phi=80^{\circ}, \theta=50^{\circ}$ and $\psi=-90^{\circ}$, the $\mathrm{NH}$ and $\mathrm{CO}$ vectors being directed up and down, and exclusively promoted helices with mixed hydrogen bond networks. Nonetheless, compromises must be found between molecular rigidity allowing stable folds and adaptability to accommodate local steric hindrance. The bicyclic motifs were prone to induce strong steric 
hindrance due to higher rigidity and crowding compared to single ring systems, which could limit their incorporation. Thus, strong clashes prevented the elongation of homo-ABOC oligoamides while the use of longer urea bonds as linkages pushed aside the consecutive bicycles and allowed the conception of highly stable oligourea helices. DABO derivative, i.e. $r \mathrm{BAC}$, have shown to be fully compatible with the oligourea canonical helix and could be incorporated in

high contents. Since a broad range of applications were developed for this foldamer family, ${ }^{53,54}$ $r$ BAC could be highly valuable to tune the oligourea properties by increasing their global and local stability, and by limiting the flexibility of proximal side chains. In parallel, the singular frameworks of $\mathrm{ABOC}$ and $\mathrm{DABO}$ residues were successfully used in asymmetric synthesis to design efficient chiral catalysts, i.e. short $\alpha, \beta$-peptide catalysts and chiral diamine ligands, to catalyse asymmetric adol and Henry reactions, respectively. The broad range of tested compounds have allowed the emergence of general rules to optimize both class of catalysts. In the future, the screening of new chiral catalysts for various reactions will be a huge task since multiple possibilities arose from both $\mathrm{ABOC}$ and $\mathrm{DABO}$, varying the nature of the substituents and the achievable reactions. Besides, multiple prospects were opened for foldamers in health and in biomaterial areas. In particular, overlaps between the side chains of the naturally occurring $\alpha$-helix and the 12/14/14-helix made this latter attractive as $\alpha$-helix mimics. Likewise, the stable 10/12-helix could be readily faced for membrane recognition to develop antimicrobial compounds and vectors for the delivery of biologically active agents.

\section{AUTHOR INFORMATION}

\section{Corresponding Author}

*E-mail: muriel.amblard@umontpellier.fr, monique.calmes@gmail.com, baptiste.legrand@umontpellier.fr 


\section{ORCID}

Pierre Milbeo: 0000-0002-6199-6636

Jean Martinez: 0000-0002-9267-4621

Muriel Amblard: 0000-0001-8922-1755

Monique Calmès: 0000-0001-7690-0206

Baptiste Legrand: 0000-0001-8931-7757

\section{Present Addresses}

†Present address: Laboratoire COBRA, UMR CNRS 6014, 1 rue Tesnière - Bât. IRCOF (no 40)

- 76821 Mont Saint-Aignan Cedex

\section{Author Contributions}

The manuscript was written through contributions of all authors. All authors have given approval to the final version of the manuscript.

\section{Funding Sources}

CNRS, MESR, ANR (ANR- 08- BLAN- 0066-01, ANR- 10- LABX- 05- 01), LabEx CheMISyst, FFCSA and WTU China.

\section{Notes}

The authors declare no competing financial interest

\section{Biographies}

Pierre Milbeo was born in Casablanca, Morocco, in 1991. He graduated from ENSC-Lille and the University of Lille (2014) with a master degree in chemical engineering and organic 
chemistry. He then carried out his Ph.D studies under the supervision of Dr. M. Calmès at the University of Montpellier (IBMM) and obtained his degree in 2017. After a first postdoctoral experience at Trinity College Dublin, Pierre joined the INSA Rouen-Normandie where he is currently doing postdoctoral research. His research interests include synthetic methodology, asymmetric synthesis and biomolecules.

Jean Martinez received both his Ph.D and Dr. Sci from the University of Montpellier, France, under the direction of Prof. F. Winternitz. He spent 3 years as a postdoctoral fellow with Dr. E. Bricas, University of Paris Sud, and then with Prof. M. Bodanszky, Case Western Reserve University, Cleveland, Ohio, USA. He joined the University of Montpellier as a full professor in both organic and medicinal chemistry. He founded the Institute of Biomolecules Max Mousseron in 2007, acting as the director until 2014. His current research interests focus on peptide chemistry, stereoselective syntheses of biomolecules, design of biomaterials, green chemistry, biology and pharmacology of neuropeptides. He is currently Emeritus Professor at the University of Montpellier.

Muriel Amblard received her Ph.D in Organic Chemistry at the University of Montpellier in France under the supervision of Prof. J. Martinez in 1991. Then, she joined the group of Dr. P. Anderson at Merck Sharp \& Dohm in Pennsylvania as a postdoctoral fellow. In 1996, she became a CNRS senior researcher and leads her research at the Institute of Biomolecules Max Mousseron in the field of peptide science. Her research interests are mainly at the interface of chemistry, biology and structural analysis for developing bioactive compounds and chemical tools that can mimic biological systems. 
Monique Calmès was graduated as a chemical engineer in 1981 from the "Ecole Supérieure de Chimie de Montpellier" (France). In 1985, she received her Ph.D from the University of Montpellier (France) under the supervision of Prof. R. Jacquier in the field of new methodologies suitable for peptide synthesis. She joined in 1987, the group of Prof. L. Gosez at the University of Louvain la Neuve (Belgium) as a postdoctoral fellow. In 1988, she obtained a permanent position at the CNRS in Montpellier and holding a position of CNRS senior researcher at the Institute of Biomolecules Max Mousseron until she retired in 2019. Her research interests concerned the constrained amino acids, foldamers and asymmetric synthesis.

Baptiste Legrand was born in Chartres, France, in 1982. He received a master degree in biochemistry and structural biology from the University of Orléans in 2006. He obtained his Ph.D from the University of Rennes 1 in 2009 under the supervision of Dr. A. Bondon. After a postdoctoral at the LCPM, ENSIC, University of Lorraine at Nancy, he joined the University of Montpellier (IBMM) in 2012 where he is currently research engineer. His research is devoted to the development of bioactive oligomers mainly focusing on the structural aspect.

\section{ACKNOWLEDGMENTS}

The authors are grateful to all the colleagues who contribute to this work, in particular to Drs. Marie Christine Averlant-Petit, Claude Didierjean, Emmanuel Aubert, Emmanuel Wenger, University of Lorraine, and Aurélien Lebrun, University of Montpellier. We thank all financial institutions and the analytical facilities of Universities of Montpellier and Lorraine who contributed to this work. Sylvie Gémeno is warmly thanked for drawing the tree of the graphical abstract. 


\section{REFERENCES}

(1) André, C.; Legrand, B.; Deng, C.; Didierjean, C.; Pickaert, G.; Martinez, J.; AverlantPetit, M. C.; Amblard, M.; Calmes, M. (S)-ABOC: A Rigid Bicyclic $\beta$-Amino Acid as Turn Inducer. Org. Lett. 2012, 14 (4), 960-963. https://doi.org/10.1021/ol203406v.

(2) Legrand, B.; André, C.; Wenger, E.; Didierjean, C.; Averlant- Petit, M. C.; Martinez, J.; Calmes, M.; Amblard, M. Robust Helix Formation in a New Family of Oligoureas Based on a Constrained Bicyclic Building Block. Angewandte Chemie 2012, 124 (45), 1142911432. https://doi.org/10.1002/ange.201205842.

(3) Legrand, B.; André, C.; Moulat, L.; Didierjean, C.; Hermet, P.; Bantignies, J.-L.; Martinez, J.; Amblard, M.; Calmès, M. 12/14/14-Helix Formation in 2:1 $\alpha / \beta$-Hybrid Peptides Containing Bicyclo[2.2.2]Octane Ring Constraints. Chemistry - A European Journal 2016, 22 (34), 11986-11990. https://doi.org/10.1002/chem.201602746.

(4) Milbeo, P.; Moulat, L.; Didierjean, C.; Aubert, E.; Martinez, J.; Calmès, M. C1-Symmetric 1,2-Diaminobicyclo[2.2.2]Octane Ligands in Copper-Catalyzed Asymmetric Henry Reaction: Catalyst Development and DFT Studies. European Journal of Organic Chemistry 2018, 2018 (2), 178-187. https://doi.org/10.1002/ejoc.201701452.

(5) Cabrele, C.; Martinek, T. A.; Reiser, O.; Berlicki, Ł. Peptides Containing $\beta$-Amino Acid Patterns: Challenges and Successes in Medicinal Chemistry. J. Med. Chem. 2014, 57 (23), 9718-9739. https://doi.org/10.1021/jm5010896.

(6) Wani, M. C.; Taylor, H. L.; Wall, M. E.; Coggon, P.; McPhail, A. T. Plant antitumor agents. VI. Isolation and structure of taxol, a novel antileukemic and antitumor agent from Taxus brevifolia https://pubs.acs.org/doi/pdf/10.1021/ja00738a045 (accessed Aug 5, 2020). https://doi.org/10.1021/ja00738a045.

(7) Umezawa, H.; Maeda, K.; Takeuchi, T.; Okami, Y. New Antibiotics, Bleomycin A and B. J. Antibiot. 1966, 19 (5), 200-209.

(8) Seebach, D.; Matthews, J. L. $\beta$-Peptides: A Surprise at Every Turn. Chemical Communications 1997, $O$ (21), 2015-2022. https://doi.org/10.1039/A704933A.

(9) Gellman, S. H. Foldamers: A Manifesto. Acc. Chem. Res. 1998, 31 (4), 173-180. https://doi.org/10.1021/ar960298r.

(10) Seebach, D.; Beck, A. K.; Bierbaum, D. J. The World of Beta- and Gamma-Peptides Comprised of Homologated Proteinogenic Amino Acids and Other Components. Chem. Biodivers. 2004, 1 (8), 1111-1239. https://doi.org/10.1002/cbdv.200490087.

(11) Ortuño, R. M. Enantioselective Synthesis of Conformationally Constrained $\beta$-Amino Acids. In Enantioselective Synthesis of $\beta$-Amino Acids; John Wiley \& Sons, Ltd, 2005; pp 117-138. https://doi.org/10.1002/0471698482.ch5.

(12) Fülöp, F. Alicyclic $\beta$-Amino Acids: Useful Synthons in Drug Research. ChemMedChem. 2000, 55 (3), 181-183. https://doi.org/10.1016/S0014-827X(00)00016-1.

(13) Kuhl, A.; Hahn, M. G.; Dumić, M.; Mittendorf, J. Alicyclic $\beta$-Amino Acids in Medicinal Chemistry. Amino Acids 2005, 29 (2), 89-100. https://doi.org/10.1007/s00726-005-0212$\mathrm{y}$.

(14) G. Davies, S.; J. Russell, A.; L. Sheppard, R.; D. Smith, A.; E. Thomson, J. Evaluating $\beta$ Amino Acids as Enantioselective Organocatalysts of the Hajos-Parrish-Eder-SauerWiechert Reaction. Organic \& Biomolecular Chemistry 2007, 5 (19), 3190-3200. https://doi.org/10.1039/B711171A. 
(15) D'Elia, V.; Zwicknagl, H.; Reiser, O. Short $\alpha / \beta$-Peptides as Catalysts for Intra- and Intermolecular Aldol Reactions. J. Org. Chem. 2008, 73 (8), 3262-3265. https://doi.org/10.1021/jo800168h.

(16) Pasco, M.; Dolain, C.; Guichard, G. Foldamers in Medicinal Chemistry. Comprehensive Supramolecular Chemistry II 2017, 89-125. https://doi.org/10.1016/B978-0-12-4095472.12565-X.

(17) Legrand, B.; Aguesseau-Kondrotas, J.; Simon, M.; Maillard, L. Catalytic Foldamers: When the Structure Guides the Function. Catalysts 2020, 10 (6), 700. https://doi.org/10.3390/catal10060700.

(18) Seebacher, W.; Schlapper, C.; Brun, R.; Kaiser, M.; Saf, R.; Weis, R. Synthesis of New Esters and Oximes with 4-Aminobicyclo[2.2.2]Octane Structure and Evaluation of Their Antitrypanosomal and Antiplasmodial Activities. European Journal of Medicinal Chemistry 2006, 41 (8), 970-977. https://doi.org/10.1016/j.ejmech.2006.04.002.

(19) Baran, A.; Günel, A.; Balci, M. Synthesis of Bicyclo[2.2.2]Octane-2,3,5,6,7,8 Hexols (Bishomoinositols) as Glycosidase Inhibitors. J. Org. Chem. 2008, 73 (12), 4370-4375. https://doi.org/10.1021/jo800553u.

(20) Manner, S.; Hansson, C.; Larsson, J. M.; Oltner, V. T.; Frejd, T. Asymmetric Baker's Yeast Reductions of Bridgehead-Substituted Bicyclo[2.2.2]Octane-2,6-Dione Derivatives Followed by Conversion into Catalytically Active BODOLs for the Diethylzinc Addition to Benzaldehyde. Tetrahedron: Asymmetry 2010, 21 (11), 1374-1381. https://doi.org/10.1016/j.tetasy.2010.06.003.

(21) Jayamurugan, G.; Gowri, V.; Hernández, D.; Martin, S.; González-Orive, A.; Dengiz, C.; Dumele, O.; Pérez-Murano, F.; Gisselbrecht, J.-P.; Boudon, C.; Schweizer, W. B.; Breiten, B.; Finke, A. D.; Jeschke, G.; Bernet, B.; Ruhlmann, L.; Cea, P.; Diederich, F. Design and Synthesis of Aviram-Ratner-Type Dyads and Rectification Studies in Langmuir-Blodgett (LB) Films. Chemistry - A European Journal 2016, 22 (30), 10539-10547. https://doi.org/10.1002/chem.201505216.

(22) Chang, L. L.; Truong, Q.; Doss, G. A.; MacCoss, M.; Lyons, K.; McCauley, E.; Mumford, R.; Forrest, G.; Vincent, S.; Schmidt, J. A.; Hagmann, W. K. Highly Constrained Bicyclic VLA-4 Antagonists. Bioorganic \& Medicinal Chemistry Letters 2007, 17 (3), 597-601. https://doi.org/10.1016/j.bmcl.2006.11.011.

(23) Park, J.-S.; Kim, K. R.; Nam, H. Y.; Yeom, C.-E.; Chough, C.; Kwon, S. H.; Ro, S.; Kim, D.-K. S. and B. M. Synthesis and Structural Analysis of 6-Aminobicyclo[2.2.1]heptane-2carboxylic Acid as a onformationally Constrained $\gamma$-Turn Mimic https://www.eurekaselect.com/83226/article (accessed Aug 5, 2020).

(24) Grygorenko, O. O. Bicyclic $\beta$-Amino Acids. Tetrahedron 2015, 71 (33), 5169-5216. https://doi.org/10.1016/j.tet.2015.05.069.

(25) Songis, O.; Didierjean, C.; Laurent, C.; Martinez, J.; Calmès, M. Asymmetric Diels-Alder Cycloaddition of 1-Aminocyclohexadiene to Chiral Acrylate: Synthesis of Enantiopure Bridgehead-Aminobicyclo[2.2.2]Octane-2-Carboxylic Acid Derivatives. European Journal of Organic Chemistry 2007, 2007 (19), 3166-3172. https://doi.org/10.1002/ejoc.200700236.

(26) Milbeo, P.; Moulat, L.; Didierjean, C.; Aubert, E.; Martinez, J.; Calmès, M. Synthesis of Enantiopure 1,2-Diaminobicyclo[2.2.2]Octane Derivatives, C1-Symmetric Chiral 1,2Diamines with a Rigid Bicyclic Backbone. J. Org. Chem. 2017, 82 (6), 3144-3151. https://doi.org/10.1021/acs.joc.7b00122. 
(27) Legrand, B.; André, C.; Moulat, L.; Wenger, E.; Didierjean, C.; Aubert, E.; Averlant- Petit, M. C.; Martinez, J.; Calmes, M.; Amblard, M. Unprecedented ChainLength-Dependent Conformational Conversion Between 11/9 and 18/16 Helix in $\alpha / \beta-$ Hybrid Peptides. Angewandte Chemie 2014, 126 (48), 13347-13351. https://doi.org/10.1002/ange.201407329.

(28) Simon, M.; Milbeo, P.; Liu, H.; André, C.; Wenger, E.; Martinez, J.; Amblard, M.; Aubert, E.; Legrand, B.; Calmès, M. 12/10-Helix in Mixed $\beta$-Peptides Alternating Bicyclic and Acyclic $\beta$-Amino Acids: Probing the Relationship between Bicyclic Side Chain and Helix Stability. Chemistry - A European Journal 2018, 24 (70), 18795-18800. https://doi.org/10.1002/chem.201804404.

(29) André, C.; Legrand, B.; Moulat, L.; Wenger, E.; Didierjean, C.; Aubert, E.; Averlant-Petit, M. C.; Martinez, J.; Amblard, M.; Calmes, M. Mixed Oligoureas Based on Constrained Bicyclic and Acyclic $\beta$-Amino Acids Derivatives: On the Significance of the Subunit Configuration for Folding. Chemistry 2013, 19 (50), 16963-16971. https://doi.org/10.1002/chem.201302829.

(30) Milbeo, P.; Simon, M.; Didierjean, C.; Wenger, E.; Aubert, E.; Martinez, J.; Amblard, M.; Calmès, M.; Legrand, B. A Bicyclic Unit Reversal to Stabilize the 12/14-Helix in Mixed Homochiral Oligoureas. Chemical Communications 2020, 56 (57), 7921-7924. https://doi.org/10.1039/D0CC02902E.

(31) Milbeo, P.; Maurent, K.; Moulat, L.; Lebrun, A.; Didierjean, C.; Aubert, E.; Martinez, J.; Calmès, M. N-Pyrrolidine-Based $\alpha / \beta$-Peptides Incorporating ABOC, a Constrained Bicyclic $\beta$-Amino Acid, for Asymmetric Aldol Reaction Catalysis. Tetrahedron 2016, 72 (13), 1706-1715. https://doi.org/10.1016/j.tet.2016.02.027.

(32) Gouverneur, V. E.; Houk, K. N.; Pascual-Teresa, B. de; Beno, B.; Janda, K. D.; Lerner, R. A. Control of the Exo and Endo Pathways of the Diels-Alder Reaction by Antibody Catalysis. Science 1993, 262 (5131), 204-208. https://doi.org/10.1126/science.8211138.

(33) Shaw, S.; White, James. D. Cis-2,5-Diaminobicyclo[2.2.2]Octane, a New Chiral Scaffold for Asymmetric Catalysis. Acc. Chem. Res. 2016, 49 (9), 1825-1834. https://doi.org/10.1021/acs.accounts.6b00286.

(34) Waki, M.; Kitajima, Y.; Izumiya, N. A Facile Synthesis of N2-Protected L-2,3Diaminopropanoic Acid. Synthesis 2002, 1981 (04), 266-268. https://doi.org/10.1055/s1981-29407.

(35) Robinson, J. A. $\beta$-Hairpin Peptidomimetics: Design, Structures and Biological Activities. Acc. Chem. Res. 2008, 41 (10), 1278-1288. https://doi.org/10.1021/ar700259k.

(36) Trabocchi, A.; Menchi, G.; Danieli, E.; Guarna, A. Synthesis of a Bicyclic $\delta$-Amino Acid as a Constrained Gly-Asn Dipeptide Isostere. Amino Acids 2008, 35 (1), 37-44. https://doi.org/10.1007/s00726-007-0636-7.

(37) Godina, T. A.; Lubell, W. D. Mimics of Peptide Turn Backbone and Side-Chain Geometry by a General Approach for Modifying Azabicyclo[5.3.0]Alkanone Amino Acids. J. Org. Chem. 2011, 76 (14), 5846-5849. https://doi.org/10.1021/jo2006363.

(38) Horne, W. S.; Gellman, S. H. Foldamers with Heterogeneous Backbones. Acc. Chem. Res. 2008, 41 (10), 1399-1408. https://doi.org/10.1021/ar800009n.

(39) Hayen, A.; Schmitt, M. A.; Ngassa, F. N.; Thomasson, K. A.; Gellman, S. H. Two Helical Conformations from a Single Foldamer Backbone: "Split Personality" in Short Alpha/Beta-Peptides. Angew. Chem. Int. Ed. Engl. 2004, 43 (4), 505-510. https://doi.org/10.1002/anie.200352125. 
(40) Cheng, R. P.; Gellman, S. H.; DeGrado, W. F. $\beta$-Peptides: From Structure to Function. Chem. Rev. 2001, 101 (10), 3219-3232. https://doi.org/10.1021/cr000045i.

(41) Kritzer, J. A.; Stephens, O. M.; Guarracino, D. A.; Reznik, S. K.; Schepartz, A. $\beta$-Peptides as Inhibitors of Protein-Protein Interactions. Bioorganic \& Medicinal Chemistry 2005, 13 (1), 11-16. https://doi.org/10.1016/j.bmc.2004.09.009.

(42) Harker, E. A.; Schepartz, A. Cell-Permeable $\beta$-Peptide Inhibitors of P53/HDM2 Complexation. ChemBioChem 2009, $10 \quad$ (6), 990-993. https://doi.org/10.1002/cbic.200900049.

(43) Sharma, G. V. M.; Reddy, K. R.; Krishna, P. R.; Sankar, A. R.; Narsimulu, K.; Kumar, S. K.; Jayaprakash, P.; Jagannadh, B.; Kunwar, A. C. Robust Mixed 10/12 Helices Promoted by "Alternating Chirality" in a New Family of C-Linked Carbo-Beta-Peptides. J. Am. Chem. Soc. 2003, 125 (45), 13670-13671. https://doi.org/10.1021/ja035752i.

(44) Martinek, T. A.; Mándity, I. M.; Fülöp, L.; Tóth, G. K.; Vass, E.; Hollósi, M.; Forró, E.; Fülöp, F. Effects of the Alternating Backbone Configuration on the Secondary Structure and Self-Assembly of Beta-Peptides. J. Am. Chem. Soc. 2006, 128 (41), 13539-13544. https://doi.org/10.1021/ja063890c.

(45) Fischer, L.; Claudon, P.; Pendem, N.; Miclet, E.; Didierjean, C.; Ennifar, E.; Guichard, G. The Canonical Helix of Urea Oligomers at Atomic Resolution: Insights into FoldingInduced Axial Organization. Angew. Chem. Int. Ed. Engl. 2010, 49 (6), 1067-1070. https://doi.org/10.1002/anie.200905592.

(46) Metrano, A. J.; Chinn, A. J.; Shugrue, C. R.; Stone, E. A.; Kim, B.; Miller, S. J. Asymmetric Catalysis Mediated by Synthetic Peptides, Version 2.0: Expansion of Scope and Mechanisms. Chem. Rev. 2020. https://doi.org/10.1021/acs.chemrev.0c00523.

(47) Yamashita, Y.; Yasukawa, T.; Yoo, W.-J.; Kitanosono, T.; Kobayashi, S. Catalytic Enantioselective Aldol Reactions. Chem. Soc. Rev. 2018, 47 (12), 4388-4480. https://doi.org/10.1039/C7CS00824D.

(48) Revell, J. D.; Wennemers, H. Investigating Sequence Space: How Important Is the Spatial Arrangement of Functional Groups in the Asymmetric Aldol Reaction Catalyst H-Pro-ProAsp-NH2? Advanced Synthesis \& Catalysis 2008, 350 (7-8), 1046-1052. https://doi.org/10.1002/adsc.200800053.

(49) White, J. D.; Shaw, S. A New Catalyst for the Asymmetric Henry Reaction: Synthesis of $\beta$-Nitroethanols in High Enantiomeric Excess. Org. Lett. 2012, 14 (24), 6270-6273. https://doi.org/10.1021/o13030023.

(50) Kannan, M.; Punniyamurthy, T. Effect of Ligand N,N-Substituents on the Reactivity of Chiral Copper(II) Salalen, Salan, and Salalan Complexes toward Asymmetric Nitroaldol Reactions. Tetrahedron: Asymmetry 2014, 25 (18), 1331-1339. https://doi.org/10.1016/j.tetasy.2014.07.013.

(51) Arai, T.; Watanabe, M.; Yanagisawa, A. Practical Asymmetric Henry Reaction Catalyzed by a Chiral Diamine-Cu(OAc)2 Complex. Org. Lett. 2007, 9 (18), 3595-3597. https://doi.org/10.1021/o17014362.

(52) Murugavel, G.; Sadhu, P.; Punniyamurthy, T. Copper(II)-Catalyzed Nitroaldol (Henry) Reactions: Recent Developments. Chem Rec 2016, 16 (4), 1906-1917. https://doi.org/10.1002/tcr.201500268.

(53) Douat, C.; Aisenbrey, C.; Antunes, S.; Decossas, M.; Lambert, O.; Bechinger, B.; Kichler, A.; Guichard, G. A Cell-Penetrating Foldamer with a Bioreducible Linkage for 
Intracellular Delivery of DNA. Angew. Chem. Int. Ed. Engl. 2015, 54 (38), 11133-11137. https://doi.org/10.1002/anie.201504884.

(54) Guichard, G.; Cussol, L.; Mauran, L.; Buratto, J.; Belorusova, A. Y.; Neuville, M.; Osz, J.; Fribourg, S.; Fremaux, J.; Dolain, C.; Goudreau, S.; Rochel, N. Structural Basis for $\alpha-$ Helix Mimicry and Inhibition of Protein-Protein Interactions with Oligourea Foldamers. Angewandte Chemie International Edition $n / a \quad$ (n/a). https://doi.org/10.1002/anie.202008992. 